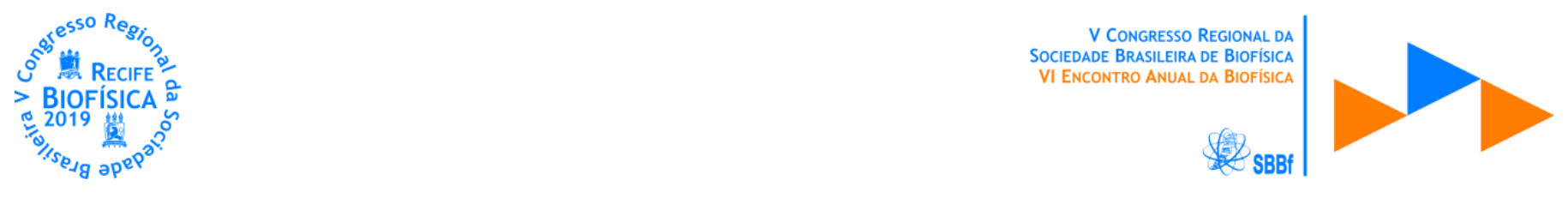

\title{
A COR E O TAMANHO INTERFERE NA INGESTÃO DE RESÍDUO SÓLIDO PELA TILÁPIA?
}

\author{
Estefani Santana do Nascimento ${ }^{1}$, Juliana de Oliveira dos Santos ${ }^{1}$, Cristiane Maria Varela de Araújo de Castro ${ }^{1}$, \\ Maria Adelia Borstelmann de Oliveira ${ }^{1}$
}

'Laboratório de Ecofisiologia e Comportamento Animal, Departamento de Morfologia e Fisiologia Animal, UFRPE

*estefesantana@gmail.com

\section{INTRODUÇÃO}

Segundo Andreoli et al. (2015) na sociedade atual perdura a ideia da obsolescência planejada, onde os produtos são projetados para terem uma durabilidade e tempo de vida menor, levando a necessidade de se comprar mais vezes o mesmo produto. Dessa forma, os mesmos são trocados por ficar obsoletos e não por se estragar, repercutindo diretamente no aumento da produção de resíduos.

O descarte de resíduos em cursos d'água é feito por pessoas que, em geral, ignoram o seu impacto no ambiente, se acumulam às margens ou no fundo dos rios e demais mananciais. Quando chove dificultam ou impedem o curso das águas provocando enchentes e eventualmente tragédias. Além disso, podem ser ingeridos por animais (PRS, 2013).

Resíduos sólidos são gerados a partir de atividades de origem industrial, doméstica, hospitalar, comercial, agrícola, de varrição entre outras e podem ser podem ser utilizados como matéria-prima. Em contrapartida, lixo pode ser entendido como algo inútil, que não pode ser reaproveitado (ANDREOLI et al., 2015).

Entre os resíduos sólidos que podem ser ingeridos pelos animais aquáticos temos as miçangas, que podem ser de plástico, vidro, entre outros; são amplamente usadas nas indústrias de roupas, bijuterias, utensílios religiosos entre outros, por isso chegam aos rios com facilidade e certa constância (ELS LAGROU, 2016).

As miçangas despertam especial interesse e curiosidade, sendo amplamente utilizadas por artesãs e artistas indígenas para a confecção de seus artefatos e utensílios. São tão contemporâneas quanto antigas, incorporadas nas principais manifestações estéticas e rituais de vários grupos indígenas, elas são apreciadas por sua diversidade de cores, tamanho, formas, qualidades de brilho e durabilidade (TUCUM, 2015).

Diversos peixes podem ingerir os resíduos sólidos presente nos rios, dentre eles podemos citar a espécie Oreochromis niloticus (tilápiado-Nilo), que é um peixe de grande importância econômica, já consumida pelos antigos egípcios há mais de 3 mil anos. Hoje, é o peixe de água doce mais cultivado e comercializado no Brasil e o quarto no mundo atrás de três espécies de carpa (OLIVEIRA, 2016; SPONCHIATO, 2017). Segundo a Organização das Nações Unidas para a Alimentação e a Agricultura (FAO), a sua produção saltou 223\% entre 2005 e 2015, totalizando mais de 219 mil toneladas anuais.

A tilápia se sobressai das demais, pelo crescimento acelerado, reprodução mais tardia (atingindo maior tamanho antes da primeira reprodução) e alta prolificidade (proporcionando a produção de grandes quantidades de alevinos), entre os peixes que podem ser cultivados em cativeiro, a tilápia destaca-se por sua resistência a doenças, tolerância ao cultivo em altas densidades e em ambientes adversos e estressantes, o que a tornou rapidamente a espécie preferida pela piscicultura brasileira (SILVA et al. 2015).

A alimentação destaca-se como uma das atividades de maior importância para o peixe, uma vez que é determinante para o seu crescimento e eficiência reprodutiva animal (EMBRAPA, 2015). A Tilápia-do-Nilo, exige uma dieta com apropriado balanço de nutrientes e energia para a manutenção das funções vitais, crescimento e reprodução. Essa exigência deve ser suprida por meio do alimento natural (plâncton e outros organismos) e/ou dos alimentos "artificiais" (ração completa). Porém, muitas vezes essa dieta pode ser empobrecida quando no ambiente está misturada a resíduos sólidos.

Diante do exposto, o presente trabalho objetiva avaliar o efeito atrativo do tamanho da miçanga ao peixe Oreochromis niloticus, observar a cor mais atrativa para a espécie $O$. niloticus, assim como verificar se a Tilápia realizará a ingestão de miçangas (resíduo sólido), visto que elas apresentam a mesma forma e tamanhos semelhantes a ração utilizada na sua dieta,

\section{MATERIAIS E MÉTODOS}

A pesquisa foi desenvolvida no Laboratório de Ecofisiologia e Comportamento Animal (LECA), do Departamento de Morfologia e Fisiologia Animal (DMFA) da Universidade Federal Rural de Pernambuco (UFRPE) e aprovado pelo Comitê de Ética da instituição sob o número $52 / 2018$.

Peixes da espécie Oreochromis niloticus foram obtidos da Estação de Aquicultura Prof. Johei Koike, localizada na UFRPE e levado ao LECA para cultivo e manutenção até utilização nos ensaios. Os alevinos utilizados nos ensaios apresentaram tamanho de $10 \pm 1 \mathrm{~cm}$ e peso de $14 \pm 2 \mathrm{~g}$.

Com o intuito de avaliar o efeito atrativo do tamanho da miçanga à tilápia, foi realizado um experimento utilizando apenas a cor marrom, uma vez que se assemelhava muito a cor da ração utilizada no cultivo. 0 tempo de realização consistiu em 2 horas, cada grupo apresentou 3 repetições ( 3 peixes mantidos individualmente em aquários), totalizando 6 indivíduos e dois grupos: GM1 (miçanga marrom de forma esferoide oblato medindo 2,5 x 2,0 mm) e GM2 (miçanga marrom esférica com diâmetro de $3 \mathrm{~mm}$ ).

Para avaliar qual a cor é mais atrativa para a espécie 0 . niloticus, foi realizado um experimento que consistiu na oferta de 10 miçangas de 3 diferentes cores (azul, vermelho e marrom) juntamente com a ração utilizada na manutenção desses animais em laboratório. Para esse experimento, 9 peixes foram mantidos individualmente em aquários de vidro com 10 litros de água de cultivo. Os grupos experimentais eram compostos por 3 indivíduos cada (mantidos individualmente), os grupos: vermelho (GV), azul (GA) e marrom 
(GM1) recebeu $100 \mathrm{mg}$ de ração acrescidos de 10 miçangas vermelhas, azul e marrom, respectivamente. Esse ensaio teve duração de 2 horas, período no qual era observada a investida do peixe à ração e às miçangas.

A taxa de ingestão das miçangas foi determinada em um período de 24 horas, para tal, 4 grupos de peixe, em triplicata, foi submetido aos seguintes tratamentos: GV, GA, GM1 e GM2. Após 24h, foi contabilizada a quantidade de miçangas restante no aquário de cada peixe e calculado média e desvio padrão. Para verificar diferenças significativas entre a taxa de ingestão, foi utilizado a ANOVA, após verificação na normalidade e homocedasticidade, e foi utilizado um $\alpha$ de $5 \%$.

\section{RESULTADOS E DISCUSSÃO}

Após a primeira exposição que consistiu no teste de tamanho, com relação ao estímulo atrativo, foi verificado que as miçangas GM1 (de menor tamanho) afundaram assim que foram adicionadas ao aquário, enquanto que as GM2 (de maior tamanho) boiaram e se misturaram com a ração ofertada.

Com relação ao estímulo atrativo das miçangas aos peixes, foi verificado que o grupo $G M 1$, que afundou rapidamente, não provocou nenhum estímulo visual às tilápias, os quais foram somente em direção à ração. Após a ingestão da ração, os peixes do GM1 se mostraram atraídos pelas miçangas no fundo do aquário.

Os peixes do GM2 ingeriram as miçangas, pois as mesmas estavam próximas a ração, porém, eram cuspidas imediatamente. Após esse comportamento inicial, os peixes apresentaram uma seleção entre a ração e as miçangas, preferindo sempre a ração.

Sendo assim, verificou-se que o Oreochromis niloticus não apresentou seletividade quanto ao tamanho, este fato, pode estar relacionado com a pouca variação de tamanho entre as duas miçangas ofertadas, e ambas estarem bem próximas ao tamanho da ração ofertada diariamente.

Com relação ao estímulo atrativo das diferentes cores, observou-se que as miçangas nas cores azul (GA) e vermelha (GV) apresentaramse mais atrativa que a marrom (GM1). A análise comportamental mostrou que os peixes dos grupos GA e GV apresentaram comportamento de ingestão das miçangas nessas cores, por várias vezes. Após a ingestão, peixes do GA cuspiam as miçangas azuis quase que imediatamente a ingestão. Porém, os peixes do GV, ingeriram todas as miçangas vermelhas assim que as mesmas foram ofertadas, apresentando uma atração maior por essa cor em relação as outras utilizadas no presente estudo (Figura 1).

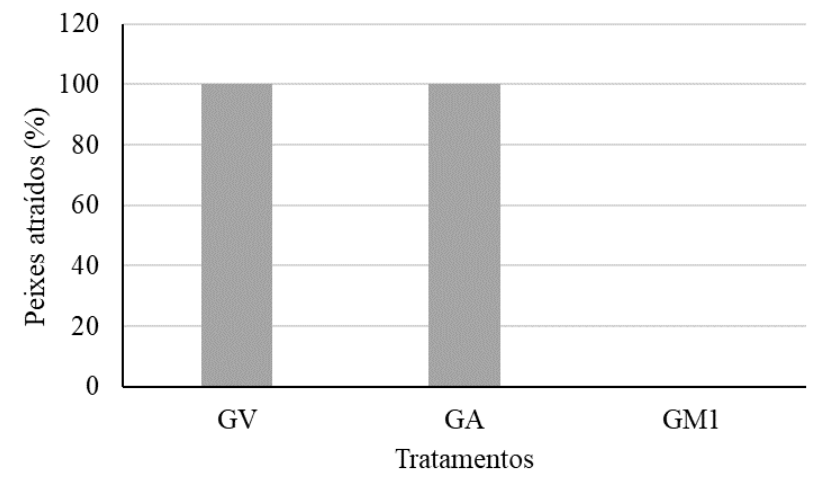

Figura 1. Percentual de peixes com estímulo atrativo em relação a cor da miçanga nos diferentes grupos experimentais: GV (miçangas vermelhas), GA (miçangas azuis) e GM (miçangas marrons).

Segundo Nielsen (2010), um olho formador de imagem pode estar baseado em dois princípios diferentes: um olho multifacetado, como dos insetos, ou uma estrutura semelhante a uma câmera, como uma única lente, como em vertebrados. 0 peixe por sua vez como um vertebrado, necessita de algum dispositivo para o foco, afim de que sejam obtidos resultados igualmente satisfatórios para distancias diferentes.

O estímulo para todas as células receptoras visuais é a radiação eletromagnética que cai em uma faixa particular de energia, luz visível. A energia da radiação eletromagnética varia inversamente com seu comprimento de onda, e nós percebemos essa variação de energia como uma variação na cor. A luz violeta, a energia mais elevada a que o olho humano responde, tem comprimento de onda de aproximadamente $400 \mathrm{~nm}$. A luz vermelha, na faixa de menor energia do espectro visível, tem comprimentos de onda entre $650 \mathrm{e}$ $700 \mathrm{~nm}$. A luz brilhante libera mais energia por unidade de tempo do que a luz pálida. As células fotorreceptoras que captam a energia da luz e a transduzem em sinais neurais estão localizadas na retina do olho do vertebrado (RANDALL et al., 2000).

Baseando-se nesse pressuposto os resultados sugerem que os peixes tem uma maior sensibilidade para perceber uma faixa de menor energia do espectro visível, uma vez que o maior estimulo atrativo foi para a busca das miçangas vermelhas.

Com relação a taxa de ingestão após $24 \mathrm{~h}$ de exposição, foi observada uma reduzida ingestão, mesmo no grupo que foi mais atrativo com relação a cor (GV) com 1,33 $\pm 1,5$ unidades. Nos demais grupos (GA e GM1) a taxa de ingestão foi nula. Estes resultados sugerem que a cor marrom foi pouco atrativa e não ingerida, a cor azul foi muito atrativa e não ingerida, indicando que os indivíduos que ingeriram as miçangas, cuspiram posteriormente. Os peixes do $\mathrm{GV}$, foram muito atraídos pela cor vermelha, mas apresentaram uma baixa taxa de ingestão, mostrando que essa cor é bem relevante para o estímulo alimentar da espécie.

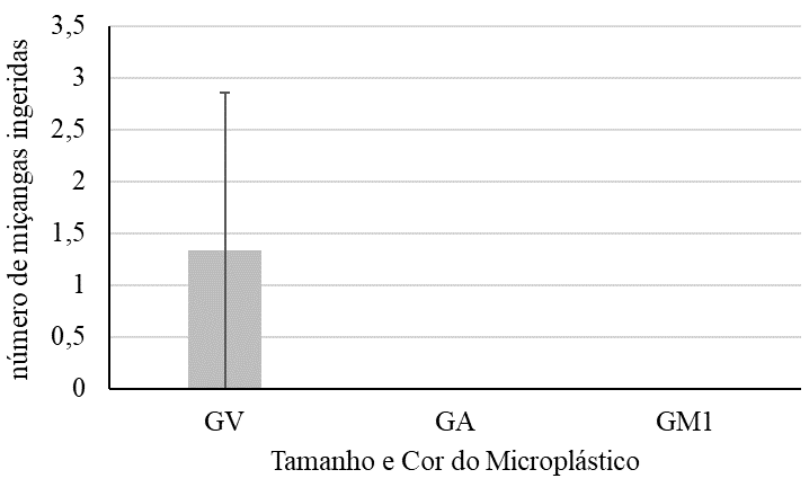

Figura 2. Taxa de ingestão de miçangas (média \pm desvio padrão) de Oreochromis niloticus expostas a diferentes cores de miçangas. Grupos GV (miçangas vermelhas), GA (miçangas azuis) e GM1 (miçangas marrons).

Segundo Silva (2015), a tilápia-do-Nilo é classificada como peixe de hábito alimentar onívoro, ou seja, se alimenta de todo tipo de material orgânico disponível na água, moluscos, sementes, vegetais de qualquer espécie, crustáceos, entre outros. Na escassez de alimentos sólidos possuem capacidade de filtrar e ingerir organismos planctônicos. A língua é usualmente rígida e pouco móvel, não contém glândulas salivares, porém apresentam botões gustativos.

Segundo Nielsen (2010), alguns peixes tem sentidos químicos que apresentam uma inacreditável acuidade. Os quimiorreceptores dos peixes são altamente sensíveis a aminoácidos, que indubitavelmente são importantes na busca de alimento.

Uma das possíveis razões para que os peixes tenham cuspido as miçangas, mesmo tendo entrado em contato direto com elas, pode ser a ausência de aminoácidos nesse pseudoalimento. Como os peixes têm botões gustativos, é provável que eles não tenham percebido nenhum tipo de substância, mesmo tendo entrado em contato direto com a miçanga. 


\section{CONCLUSÕES}

Os peixes Oreochromis niloticus, não apresentaram seletividade quanto ao tamanho. Com relação a cor as miçangas nas cores azul (GA) e vermelha (GV) apresentaram-se mais atrativa que a marrom (GM1). E no que se refere a taxa de ingestão após $24 \mathrm{~h}$ de exposição, foi observada uma reduzida ingestão, mesmo no grupo que foi mais atrativo com relação a cor.

\section{REFERÊNCIAS}

ANDREOLI, C.V.; ANDREOLI, F.N.; TRINDADE, T.V.; HOPPEN,C. Resíduos sólidos: origem, classificação e soluções para destinação final adequada. Disponível em: Disponível em: <http://www.agrinho.com.br/materialdoprofessor/residuossolidos-origem-classificacao-e-solucoes-para-destinacao-finaladequada> Acessado em: 10 abr. 2019.

LAGROU, E. Disponível em: <https://www.academia.edu/36181121/2016_No_caminho_da_mi\% C3\%A7anga._Um_mundo_que_se_faz_de_contas._Catalogue> Acessado em: 12/04/2019.

MORO, G. V.; RODRIGUES, A. P. O.; Rações para organismos aquáticos: tipos e formas de processamento. Embrapa Pesca e Aquicultura, Palmas, TO, 2015.

OLIVEIRA, M.; A vez da tilápia, 2016. Disponível em:<http://revistapesquisa.fapesp.br/2016/11/18/a-vez-datilapia/> Acessado em: 13 abr. 2019.

PEREIRA, R.S. Identificação e caracterização das fontes de poluição em sistemas hídricos. Revista Eletronica de Recursos Hidricos. IPHUFRGS.v1, n.1.p.20-36.2004. Disponível em: <http://www.abrh.org.br/informacoes/rerh.pdf>Acessado em: 14 abr. 2019.

SILVA, G. F.; MACIEL, L. M.; DALMASS, M. V.; GONÇALES, M. T. Tilápia-do-nilo : criação e cultivo em viveiros no estado do paraná, Curitiba, p. 12- 285, 2015.

SPONCHIATO, DIOGO.; Tilápia, o peixe que dominou o Brasil, 2017. Disponível em: <https://saude.abril.com.br/alimentacao/tilapia-opeixe-que-domina-o-brasil/> Acessado em 13 abr. 2019.

TUCUM. Os caminhos da miçanga, 2015. Disponível em: <http://site.tucumbrasil.com/os-caminhos-da-micanga/> Acessado em: 10 abr. 2019

NIELSEN, K. Fisiologia Animal: adaptação e meio ambiente. 5. ed. São Paulo: Santos, p. 548, 2010.

NIELSEN, K. Fisiologia Animal: adaptação e meio ambiente. 5. ed. São Paulo:

Santos, p. 536, 2010.

RANDALL, D.; BURGGREN, W.; FRENCH, K. Fisiologia Animal: mecanismos e adaptações. 4. ed. Rio de Janeiro: Guanabara Koogan, p. $238-239,2000$. 